\title{
If Coexist, Hypertriglyceridemia and Not Chronic Alcoholism is a More Direct and Immediate Cause of Acute Pancreatitis: A Case Report and Review of Literature
}

\section{Mathur $\mathrm{AK}^{*}$ and $\mathrm{Ho} \mathrm{L}$}

Hemet Valley Medical Center, Western University of Health Sciences, USA

\begin{abstract}
In a patient who is a chronic alcoholic and also has hypertriglyceredemia, the latter is a more likely and important cause of acute pancreatitis. Even though alcohol is the most common cause of acute pancreatitis, but if there is no binge drinking in a chronic alcoholic patient who also has concomitant hypertriglyceredemia, then latter is the more likely cause of acute pancreatitis. We present a similar case where a chronic alcoholic person developed acute pancreatitis with normal blood alcohol levels and severe elevation of serum triglyceride levels.
\end{abstract}

Keywords: Acute pancreatitis; Chronic alcoholism and hypertriglyceridemia

\section{Introduction}

A 38-year-old Caucasian male presented to our emergency department with complaints of sudden onset of abdominal pain associated with nausea, chills, and back pain for one day. The patient had a history of binge drinking and last drink was two days prior to hospitalization. Past medical history was significant for well controlled hypertension for which he took lisinopril. He never had any surgeries. Alcohol level was not elevated upon admission. Patient denied any history of smoking or street drug abuse. He denied dizziness, headaches, and shortness of breath, chest pain, vomiting, diarrhea, constipation, fevers and dysuria. Patient reported allergy to penicillin [1-5].

At presentation in the emergency room, the patient was very hypotensive with systolic blood pressure in 70 s, tachycardic with heart rate in $120 \mathrm{~s}$, and seemed to be in moderate respiratory distress. The only other positive finding on physical exam was moderate and diffuses abdominal tenderness. Grey Turner's and Cullen's signs were negative. A CT scan of the chest, abdomen and pelvis demonstrated severe pancreatitis with high probability of pancreatic necrosis (Figures 1 and 2). There was a large amount of fluid extending from the pancreas into the pelvis. There was no definitive normal pancreatic tissue seen. On admission: $\mathrm{pH}$ was 7.06 , bicarb $5.4 \mathrm{meq} / \mathrm{L}$, WBC $8.7 \mathrm{x}$ 103/L, hemoglobin $16.0 \mathrm{~g} / \mathrm{dL}$, hematocrit $45 \%$, potassium $1.0 \mathrm{meq} / \mathrm{L}$, calcium $5.9 \mathrm{mEq} / \mathrm{L}, \mathrm{BUN}$ 9, lipase $69 \mathrm{U} / \mathrm{L}, \mathrm{Cr} 8.4$, lactic acid 5.6, blood

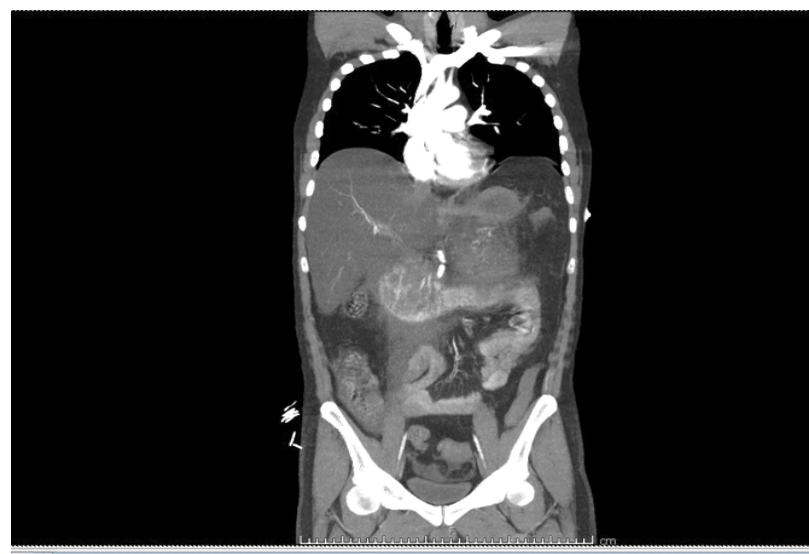

Figure 1: Coronal view of CT abdomen pelvis showing severe pancreatitis. glucose $121 \mathrm{mg} / \mathrm{dL}$, AST $78 \mathrm{iU} / \mathrm{L}$. Triglycerides $4122 \mathrm{mg} / \mathrm{dL}$. Patient was intubated and sedated, started on IV fluids, vasopressors, and IV Meropenem and admitted to the medical intensive care unit. Serum electrolytes were replaced. Bicarbonate drip was started. An urgent nephrology consult was also obtained. A temporary HD catheter was placed, and the patient received hemodialysis. Forty-eight hours after admission, his labs showed calcium $4.8 \mathrm{mEq} / \mathrm{L}$, hematocrit $24.3 \%$., BUN $8 \mathrm{mg} / \mathrm{dL}$, creatinine $2.73 \mathrm{mg} / \mathrm{dL}$, and base deficit of $9 \mathrm{mEq} / \mathrm{L}$ [6-17].

During the next few hours, clinically there was no improvement in patient's condition despite appropriate and adequate resuscitative measures including but not limited to IV fluids, vasopressors, antibiotics and hemodialysis.

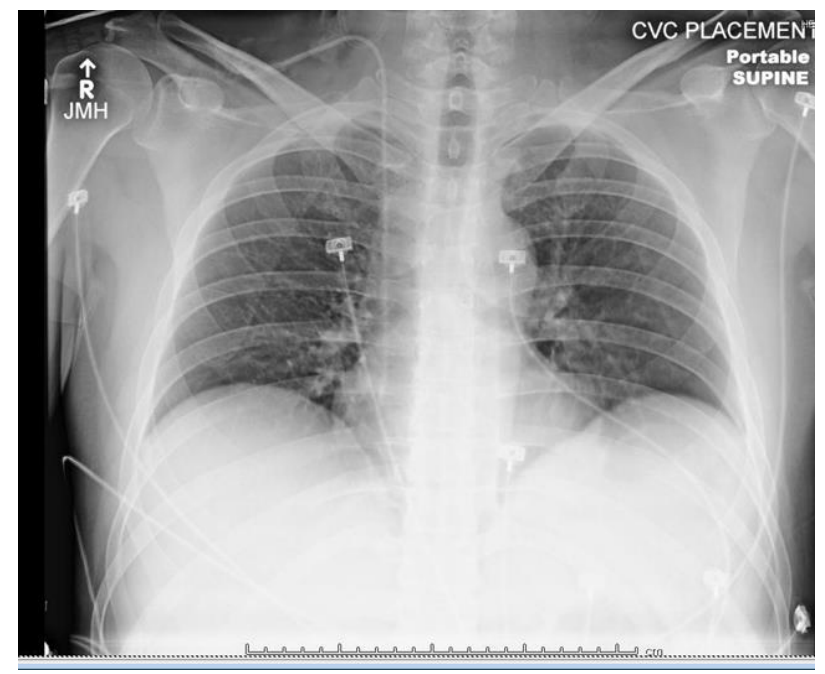

Figure 2: Chest $\mathrm{X}$-ray showing pulmonary edema as a result of pancreatitis.

*Corresponding author: Arvind K Mathur, Hemet Valley Medical Center, Western University of Health Sciences, CA, USA, Tel: 909-206-8185; E-mail: amathur@llu.edu

Received July 25, 2018; Accepted August 07, 2018; Published August 14, 2018

Citation: Mathur AK, Ho L (2018) If Coexist, Hypertriglyceridemia and Not Chronic Alcoholism is a More Direct and Immediate Cause of Acute Pancreatitis: A Case Report and Review of Literature. Hepatol Pancreat Sci 2: 114.

Copyright: (c) 2018 Mathur AK, et al. This is an open-access article distributed under the terms of the Creative Commons Attribution License, which permits unrestricted use, distribution, and reproduction in any medium, provided the original author and source are credited. 
Citation: Mathur AK, Ho L (2018) If Coexist, Hypertriglyceridemia and Not Chronic Alcoholism is a More Direct and Immediate Cause of Acute Pancreatitis: A Case Report and Review of Literature. Hepatol Pancreat Sci 2: 114.

Page 2 of 2

Considering the poor prognosis and no improvement in the clinical condition, the family decided to withdraw care and the patient expired soon after.

\section{Conclusion}

Between alcohol and hypertriglyceridemia, latter is the more important cause of acute pancreatitis.

Acute pancreatitis is a potentially life threatening condition with a worldwide increase in incidence [1]. Hypertriglyceridemia is the third most important cause of the acute pancreatitis after gallstone disease and alcohol consumption [2,3]. In contrast, during pregnancy, hypertriglyceridemia is the most common cause of acute pancreatitis [4].

Our patient was a moderate drinker who denied any binge drinking but had severe elevations of serum triglycerides. Association of chronic alcoholism with chronic pancreatitis is a well-known phenomenon, especially after Heinrich Claessen in 1842 [5] and Nikolaus Friedreich in 1878 [6] coined the term "drunkard pancreas". More confirmatory reports of association between chronic alcoholism and chronic pancreatitis continued to emerge in early and middle 20th centuries with several case reports and autopsy studies [7-9]. Whether chronic alcoholism directly, and independent of any other mechanism, triggers acute pancreatitis is unclear until now.

Moreover, there is no definitive amount of alcohol one needs to consume for an acute episode of pancreatitis. A study by Weiner et al suggests that occurrence and severity of pancreatitis in alcoholics does not correspond to the amount of alcohol ingested [10]. Binge drinking may be a causative factor for acute pancreatitis however. "Relationship of the attack to an alcoholic binge or a night's over-indulgence was of paramount importance, but in many, the amount of alcohol consumed was not necessarily greater than, or indeed as much as, that taken with impunity on previous occasions" [11]. Since binge drinking and hypertriglyceridemia can co-occur, it is difficult to gauge the effects of individual causes on incidences of acute pancreatitis, and that the true incidence of hypertriglyceridemia associated acute pancreatitis may actually be unknown [12-15]. Our young patient too denied any binge drinking and only consumed moderate amount of alcohol every week. Additionally, his last drink was more than 96 hours before presentation and the serum alcohol levels were within normal limits at presentation. This indicates that it is not chronic alcoholism but severe hypertriglyceridemia was the immediate trigger of acute pancreatitis in our patient.

Alterations in lipoprotein metabolism due to primary (genetic) or secondary causes, such as diabetes, hypothyroidism, obesity, pregnancy, renal failure, alcohol, and drugs like isotretinoin, glucocorticoids, protease inhibitors, bile acid binding resins, estrogen, $\beta$ blocker, tamoxifen, thiazide, cyclosporine [16] can cause severe hypertriglyceridemia which in turn can cause acute pancreatitis. In our patient, chronic alcoholism is the most likely cause of hypertriglyceridemia, since no other causes could be ascertained from history and labs. Usually a serum triglyceride level of greater than $1000 \mathrm{mg} / \mathrm{dL}$ is associated with acute pancreatitis [3]. While severe hypertriglyceridemia can be a cause of acute pancreatitis, a mild to moderate hypertriglyceridemia can occur as an epiphenomenon of acute pancreatitis [17]. Chylomicrons are triglyceride rich lipoprotein molecules, which are the main factors responsible for injury to pancreatic acinar cells. These cells release stored lipase and inflammatory markers, leading to widespread inflammatory injury and necrosis, which follows pancreatic injury. In rare cases, the injury can be so severe as to cause multi-organ failure, as occurred in our patient, who very rapidly developed acute cardiorespiratory failure, acute kidney injury and shock liver. As in case of spontaneous bacterial peritonitis [18], rapid diagnosis and treatment is imperative.

\section{References}

1. Singla A, Csikesz NG, Simons JP, Li YF, Ng SC, et al. (2009) National hospital volume in acute pancreatitis: analysis of the Nationwide Inpatient Sample 1998-2006. HPB (Oxford) 11: 391-397.

2. Fortson MR, Freedman SN, Webster PD (1995) Clinical assessment of hyperlipidemic pancreatitis. Am J Gastroenterol 90: 2134-2139.

3. Toskes PP (1990) Hyperlipidemic pancreatitis. Gastroenterol Clin North Am 19: 783-791.

4. Chang CC, Hsieh YY, Tsai HD, Yang TC, Yeh LS, Hsu TY, et al. (1998) Acute pancreatitis in pregnancy. Zhonghua Yi Xue Za Zhi (Taipei) 61:85-92.

5. Claessen H, Krankheiten D, Bauchspeicheldrüse D, Köln: DuMont-Schauberg 1842.

6. Friedreich $N$ (1878) Diseases of the pancreas. In: Ziemssen $\mathrm{H}$, editor Cyclopedia of the Practice of Medicine 549-630.

7. Egdahl A (1940) A review of one hundred and five reported cases of acute pancreatitis, with special reference to etiology; with report of two cases. Johns Hopkins Hospital Bulletin Arch Surg 18:130-136.

8. Clark E (1942) Pancreatitis in acute and chronic alcoholism. Am J Dig Dis 9 428-431.

9. Myers W, Keeper CS (1934) Acute pancreatic necrosis in acute and chronic alcoholism. N Engl J Med 110: 1376-1380.

10. Weiner H, Tennant R, (1938) A statistical study of acute hemorrhagic pancreatitis (hemorrhagic necrosis of pancreas). Am J Med Sci 196.

11. Marks IN, Bank S, (1963) The Aetiology, Clinical Features and Diagnosis of Pancreatitis in the South Western Cape; a Review of 243 Cases. S Afr Med J, 37: 1039-1053.

12. Cameron JL, Capuzzi DM, Zuidema GD, Margolis S, et al. (1973) Acute pancreatitis with hyperlipemia: the incidence of lipid abnormalities in acute pancreatitis. Ann Surg 177: 483-489.

13. Dominguez-Munoz JE, Malfertheiner $\mathrm{P}$, Ditschuneit $\mathrm{HH}$, Blanco-Chavez J, Uhl W, et al. (1991) Hyperlipidemia in acute pancreatitis. Relationship with etiology, onset, and severity of the disease. Int J Pancreatol 10: 261-267.

14. Dominguez-Munoz JE, Junemann F, Malfertheiner $P$ (1995) Hyperlipidemia in acute pancreatitis. Cause or epiphenomenon? Int J Pancreatol 18: 101-106.

15. Sekimoto M, Takada T, Kawarada Y, Hirata K, Mayumi T, et al. (2006) JPN Guidelines for the management of acute pancreatitis: epidemiology, etiology, natural history, and outcome predictors in acute pancreatitis. J Hepatobiliary Pancreat Surg 13: 10-24.

16. Hegele RA, (2003) Monogenic dyslipidemias: window on determinants of plasma lipoprotein metabolism. Am J Hum Genet, 2001 69: 1161-1177.

17. Yadav D, Pitchumoni CS (2003) Issues in hyperlipidemic pancreatitis. J Clin Gastroenterol 36: 54-62.

18. Kim JJ, Tsukamoto MM, Mathur AK, Ghomri YM, Hou LA, et al. (2014) Delayed paracentesis is associated with increased in-hospital mortality in patients with spontaneous bacterial peritonitis. Am J Gastroenterol 109:1436-1442. 